\title{
One simple and efficient technical method of total RNA extraction
}

\author{
Wei Jiang ${ }^{1}$, Lizhou Jia ${ }^{2}$, Gradimir N. Misevic ${ }^{3^{*}}$ \\ ${ }^{1}$ Medical Center for Digestive Diseases, The Second Affiliated Hospital of Nanjing Medical University, Nanjing, Jiangsu, \\ 210011, China; \\ ${ }^{2}$ Key Laboratory of Antibody Technology, National Health and Family Planning Commission, Nanjing Medical University, \\ Nanjing, Jiangsu, 211166, China; \\ ${ }^{3}$ Laboratory of Bioenergetics/Microbiology, University of Geneva, Switzerland.
}

\begin{abstract}
In this article, a convenient and efficient approach has been developed to isolate total RNA from cells. Conventional RNA isolation protocol is time-consuming, so to improve this, a modified method was introduced to eliminate ethanol residue by using a tip complex during the process of RNA extraction. It saves time by isolating RNA in this way and achieves high yields. Additionally, the quality of RNA is guaranteed and verified to be applicable for PCR, cDNA synthesis and reverse transcription PCR.
\end{abstract}

Keywords: RNA extraction, quality, ethanol

\section{INTRODUCTION}

RNA extraction technology is essential for molecular biology research. Targeting at microRNA or long non-coding RNA to diagnose or estimate the prognosis of various tumors are widely proceed ${ }^{[1,2]}$. The fundamental step of such research is isolating high quality RNA of cells. Unfortunately, ribonucleases (RNases) that exist in almost all cells are responsible for the degradation of RNA, which results in concentrations of RNA not being able to meet experiment requirements, especially under the circumstance of raw material shortage ${ }^{[3,4]}$. This means it is of great significance to isolate high concentrations of cells' or tissues' $\mathrm{RNA}^{[5]}$. Also the traditional method of eliminating ethanol consumes too much time. Hence, a simple and efficient method was utilized during our research, which can not only produce total RNA of better quality, but also save RNA extraction time.

*Correspondence to: Gradimir N. Misevic, Laboratory of Bioenergetics/Microbiology, University of Geneva, Switzerland. E-mail: gradimir@gimmune.com.

The authors have declared no conflict of interests.

\section{MATERIALS AND METHODS}

\section{Materials}

Human embryonic kidney cells 293 (293 cells), agarose (Invitrogen, USA), 10,000 $\times$ SolarRed nucleic acid dye (Solarbio, Beijing, China), $1 \times$ TAE running buffer including: Tris base 242 g, EDTA 100 $\mathrm{mL}$ (concentration: $0.5 \mathrm{~mol} / \mathrm{L} ; \mathrm{pH} 8.0$ ), acetic acid $57.1 \mathrm{~mL}$, and deionized water to volume $50 \mathrm{~L}$. Loading buffer, DL500 DNA Marker (TaKaRa, Japan), $\mathrm{TRIzol}^{\mathrm{TM}}$ reagent (Invitrogen, USA). All aqueous solutions were prepared in $0.1 \%$ DEPC-water. The water was NanoPure-distilled quality, obtained from a Synergy Water Purification System (Milli-Q, Millipore, USA).

\section{Laboratory equipment}

High speed refrigerated centrifuge (5417R, Eppendorf, USA), safe microcentrifuge tubes (Eppendorf, USA), nucleic acid electrophoresis (Bio-Rad, USA), nucleic acid electrophoresis tank (Tanon, Shanghai, China), ChemiDoc ${ }^{\mathrm{TM}}$ XRS+ UV image system (BioRad, USA), Nanodrop ND-1000 spectrophotometer 
(Thermo Scientific, USA), Palm micro centrifuge (Dragonlab Beijing, China), Peltier thermal cycler (Bio-Rad, USA), Thermo mixer (Thermo Scientific, USA), TC20 automated cell counter counts (Bio-Rad, USA). Centrifuge tubes not supplied in kits were autoclaved in clean RNase-free reservoirs and certified filtered pipette tips were used.

\section{Modified procedure for total RNA extraction}

The 293 human embryonic kidney cells were collected from a $75 \mathrm{~cm}^{2}$ cell culture flask and RNA was extracted from the cells using TRIzol ${ }^{\mathrm{TM}}$ reagent $^{[6,7]}$. The procedure of RNA extraction followed the instructions provided by Invitrogen. The TRIzol mixture was separated into twenty equal portions and randomly divided into two groups (group A and B).
The traditional method of eliminating the ethanol is by vacuuming dry the RNA pellet after discarding the supernatant. Some researchers have eliminated this step by pipetting the ethanol directly; however, it may pipette the extraction of RNA because the volume of the ethanol can't be counted exactly.

The modified method used here added one step to the traditional method, by using a tip complex that was made up of a $200 \mu \mathrm{L}$ tip with a $10 \mu \mathrm{L}$ tip attached to the front to eliminate the residue ethanol (Fig. 1). The modified method utilized siphonage to pipette the residue ethanol automatically, each time pipetting about $2 \mu \mathrm{L}$ of ethanol for more precise management. Group A used the traditional method while group B used the modified method. The time to eliminate the ethanol was recorded as well as concentration and absorbency ratio.
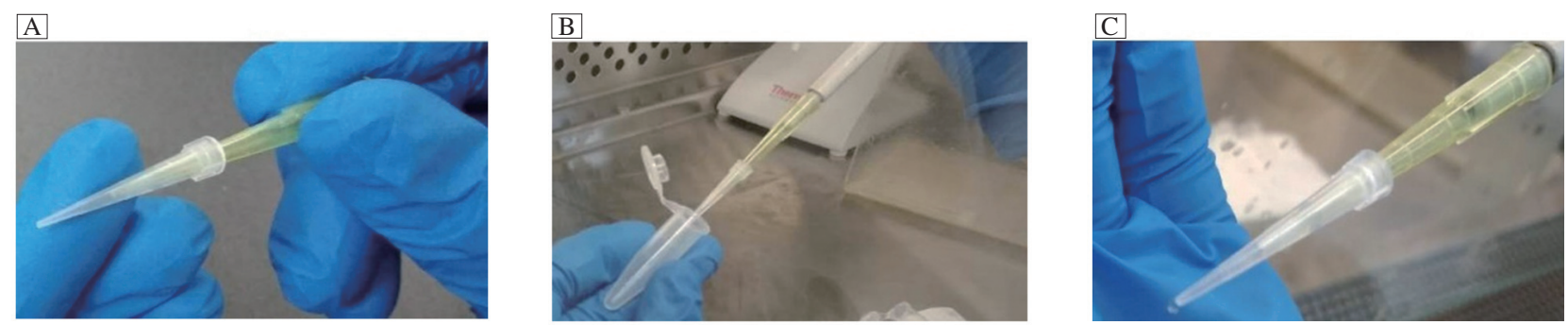

Fig. 1 The construction of the tip complex. (A) The insertion of a $200 \mu \mathrm{L}$ tip into a $10 \mu \mathrm{L}$ tip. (B) Using a $20 \mu \mathrm{L}$ pipette to connect to the above and insert into the microcentrifuge tube without pressing the pipette. (C) After removal, and pressing the pipette.

\section{Nucleic acid electrophoresis}

A $10 \mu \mathrm{L}$ RNA sample was used with $10 \times$ loading buffer $1 \mu \mathrm{L}$ added to it, then the samples were separated on a $2 \%(W / V)$ agarose gel containing ethidium bromide and photographed under UV light. The ratio of luminosity in $28 \mathrm{~S} / 18 \mathrm{~S}$ was analyzed in all samples using the Agilent 2100 bio analyzer system.

\section{Reverse transcription-polymerase chain re- action (RT-PCR)}

Total RNA extraction was completed following the Quant Script kit manufacturer's instructions for reverse transcription PCR. RNA was reverse transcribed to generate single-stranded cDNA, then the GAPDH gene fragment (197 bp) was amplified through PCR. Lastly, the products were separated on a $2 \%(W / V)$ agarose gel containing ethidium bromide and photographed under UV light.

\section{Statistical analysis}

The data was expressed as mean $\pm \mathrm{SD}$ and analyzed by paired two-sided Student's $t$ tests. $P<0.05$ was considered significant.

\section{RESULTS AND DISCUSSION}

The TRIzol ${ }^{\mathrm{TM}}$ reagent protocol is widely used for isolating RNA from cells and tissues. During the research, a modified TRIzol ${ }^{\mathrm{TM}}$ reagent protocol for RNA extraction was introduced which was based on the traditional method of eliminating the ethanol.

The twenty samples were randomly divided into two groups. The time of ethanol elimination, $\mathrm{A}_{260} / \mathrm{A}_{280}$ (requirements for $\mathrm{A}_{260} / \mathrm{A}_{280}$ are 1.8 to 2.0) and the concentration of all samples RNA were recorded (Fig. 2). The result displayed that group B was able to more efficiently promote the concentration of RNA extraction compared to group A. Besides, it can also reduce RNA extraction time. All samples at the ratio of $\mathrm{A}_{260} / \mathrm{A}_{280}$ showed luminosity of around 1.88 (Table 1), which meant samples had no contamination.

Gel electrophoresis was used to test the integrity of RNA. The outcome displayed that all samples had three clear stripes, including 28S rRNA, 18S rRNA, $5 \mathrm{~S}$ rRNA, with the average ratio of luminosity of 28S/18S showing 2.0, which revealed that the integrity of RNA was guaranteed (Fig. 3). 

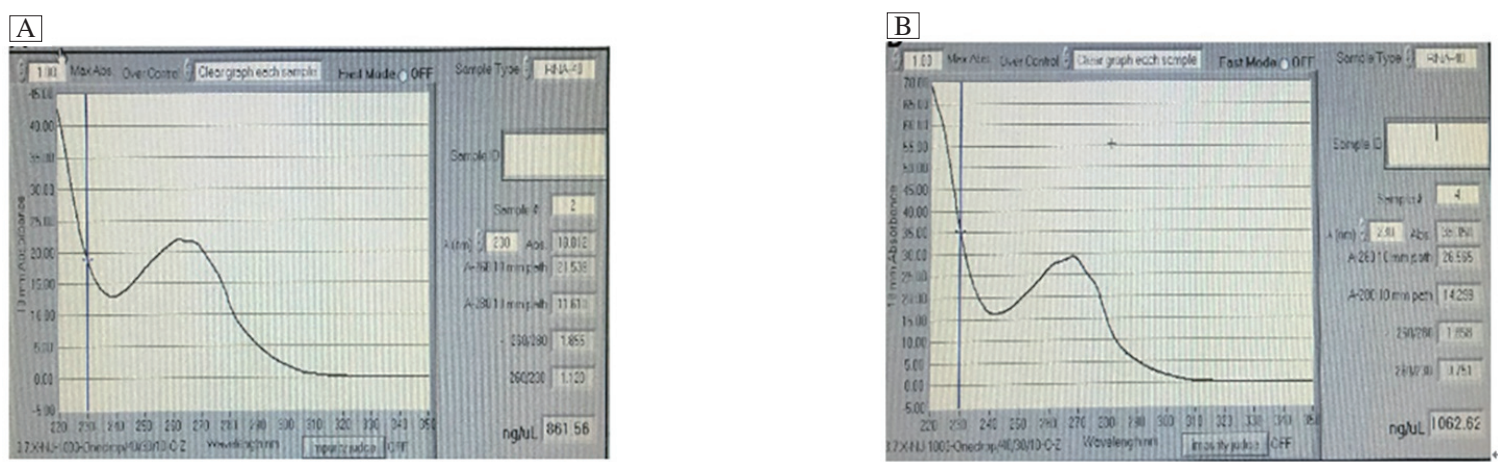

C

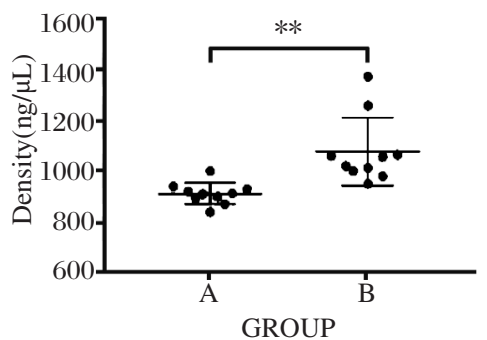

D

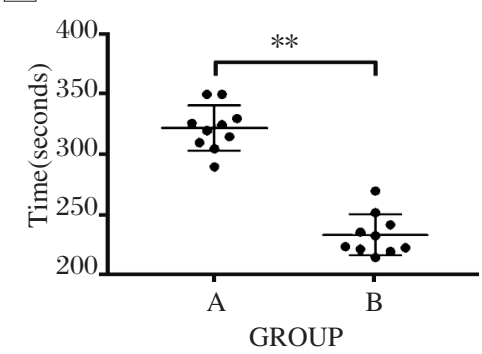

E

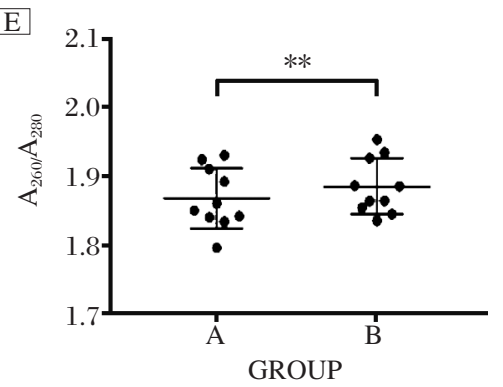

Fig. 2 Characterization of density, time, $\mathbf{A}_{260} / \mathbf{A}_{280}$ between group $\mathbf{A}$ and $\mathbf{B}$. (A) One sample from group A. (B) One sample from group B. (C) Comparison of RNA concentration. (D) Comparison of the time consuming of ethanol elimination. (E) Ratio of $\mathrm{A}_{260} / \mathrm{A}_{280}$ comparison. ${ }^{* *} P<0.01$.

Table 1 Absorbency ratios $\left(\mathbf{A}_{260} / \mathbf{A}_{280}\right)$, time of eliminating ethanol and density of RNA extraction from 293 cells

\begin{tabular}{lccc}
\hline Group & RNA concentration $(\mathrm{ng} / \mu \mathrm{L})$ & Time of eliminating ethanol $(\mathrm{s})$ & $\mathrm{A}_{260} / \mathrm{A}_{280}$ ratio \\
\hline $\mathrm{A}$ & $912.02 \pm 42.64$ & $322.10 \pm 18.75$ & $1.88 \pm 0.04$ \\
$\mathrm{~B}$ & $1,077.51 \pm 133.07$ & $233.70 \pm 17.03$ & $1.87 \pm 0.04$ \\
\hline
\end{tabular}

Values are means $\pm \mathrm{SD}(n=10)$.

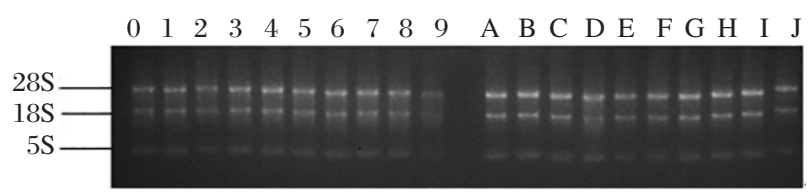

Fig. 3 The outcome of RNA ectraction in gel electrophoresis. Group A contained the stripe from A to J, while group B included the stripe from 0 to 9 . The upper stripe represented $28 \mathrm{~S}$ rRNA, the middle one was 18S rRNA and the lower one was $5 \mathrm{~S}$ rRNA.

The degradation of RNA can result in the failure of RT-PCR ${ }^{[8]}$. The RNA isolated from 293 cells was used for RT-PCR to monitor the intactness and stability of RNA. The cDNA was compounded first, and then the GAPDH gene fragment was amplified. The RT-PCR result revealed that all samples had a clear stripe, which also proved the integrity of the RNA isolation (Fig. 4).

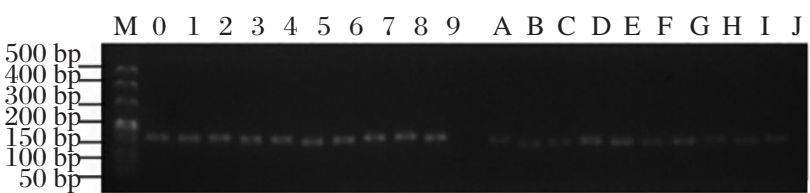

Fig. 4 The RT-PCR outcome of samples. The first lane was the DL 500 Marker. Group A contained the stripe from A to J, group B included the stripe from 0 to 9.
In conclusion, the modified method introduced here is simple and efficient for RNA extraction. For this experiment, a tip complex was used to eliminate the residue ethanol. The modified method makes for an improvement in RNA quality while consuming less time under the guarantee of RNA integrity. This report suggests that the modified method is feasible and can be applied in RNA extraction.

\section{References}

[1] Wieczorek E, Reszka E. mRNA, microRNA and lncRNA as novel bladder tumor markers. Clin Chim Acta, 2018, 477: 141-53.

[2] Wu XS, Wang F, Liu YB, et al. LncRNA-PAGBC acts as a microRNA sponge and promotes gallbladder tumorigenesis. EMBO Rep, 2017, 18(10): 1837-53.

[3] O’Leary TJ. Reducing the impact of endogenous ribonucleases on reverse transcription-PCR assay systems. Clin Chem, 1999, 45(4): 449-50.

[4] Barbas A, Matos RG, Arraiano CM, et al. New insights into the mechanism of RNA degradation by ribonuclease II: identification of the residue responsible for setting the RNase II end product. J Biol Chem, 2008, 283(19): 13070-6.

[5] Butt RH, Delaney A, Coorssen JR, et al. Enabling coupled quantitative genomics and proteomics analyses 
from rat spinal cord samples. Mol Cell Proteomics, 2007, 6(9): 1574-88.

[6] Chomczynski P, Sacchi N. Single-step method of RNA isolation by acid guanidinium thiocyanate-phenol-chloroform extraction. Anal Biochem, 1987, 162(1): 156-9.

[7] Chomczynski P. A reagent for the single-step simultaneous isolation of RNA, DNA and proteins from cell and tissue samples. Bio Techniques, 1993, 15(3): 532-4, 536-7.

[8] Wang T, Zhang N, Du L. Isolation of RNA of high quality and yield from Ginkgo biloba leaves. Biotechnol Lett, 2005, 27(9): 629-33.

(Received 14 February 2018, Revised 10 March 2018, Accepted 15 March 2018) 